\title{
PROJETO DE UMA CELA BRAILLE DE BAIXO CUSTO
}

\author{
Design of a low cost Braille cell
}

\author{
Heloise Dellagnelo Torres - Universidade do Vale do Itajaí/Brasil \\ Alejandro Rafael Garcia Ramirez - Universidade do Vale do Itajaí/Brasil
}

\begin{abstract}
RESUMO: O artigo tem como objetivo projetar uma única Cela Braille que proporcione a acessibilidade a leitura para pessoas com deficiência visual, tendo como premissa o baixo custo para permitir o acesso do dispositivo para pessoas de diversas classes sociais. Este produto permite o uso tanto por usuários que estão no processo de aprendizado do código Braille, como por leitores que já possuem esta alfabetização. O dispositivo pode ser utilizado em casa, na escola e em qualquer local que disponha de um computador com porta USB. O embasamento técnico científico foi tido por meio de trabalhos precedentes onde ideias similares foram desenvolvidas, o intuito foi aprimorá-los incluindo caracteres no programa de computador e um botão auxiliar para controlar a velocidade de leitura. Realizou-se uma pesquisa de mercado para encontrar os componentes adequados para o projeto, onde priorizou-se a qualidade, as dimensões e o custo das peças. O desenho do dispositivo foi feito em um software de Desenho Auxiliado por Computador (CAD) para que fosse impresso tridimensionalmente posteriormente. Utilizou-se o software Arduino IDE para fazer a programação do hardware que traduz textos digitados no computador para caracteres Braille diferenciando letras maiúsculas, letras minúsculas e números. $\mathrm{O}$ projeto foi validado utilizando trabalhos antecedentes, testes que envolveram o hardware e o dispositivo físico, e com uma simulação computacional.
\end{abstract}

Palavras-chave: Deficiência Visual. Tecnologia Assistiva. Acessibilidade.

\begin{abstract}
The article aims to design a single Braille cell that provides readability for the visually impaired, having as its premise the low cost to allow the device access to people of different social classes. This product allows it uses by users who are in the process of learning the Braille code, as well as readers who already have this knoledge. The device can be used at home, at school, and anywhere that has a computer with a USB port. The scientific and technical basis was inspired on previous works where similar ideas were developed, the aim was to improve them by including characters in the computer program and an auxiliary button to control the reading speed. A market research was conducted to find the appropriate components for the project, where the quality, the dimensions and cost of the parts were prioritized. The device was designed using a Computer Aided Design (CAD) software to be printed three-dimensionally later. The Arduino Software (IDE) was used to program the hardware that translates a digital text into Braille characters, distinguishing between uppercase letters, lowercase letters, and numbers. The project was validated using previous works, tests involving the hardware and the physical device, and with a computer simulation.
\end{abstract}

Keywords: Visual Impairment. Assistive Technology. Accessibility.

Educação, Psicologia e Interfaces, Volume 3, Dossiê Inclusão e Diversidade, p. 135-149, 2019 ISSN: 2594-5343. DOI: https://doi.org/10.37444/issn-2594-5343.v3i4.189 


\section{INTRODUÇÃO}

No Brasil são registradas mais de 506 mil pessoas com deficiência visual incapazes de enxergar e mais de 6 milhões são registradas como pessoas com deficiência visual com grande dificuldade de enxergar, conforme o Instituto Brasileiro de Geografia e Estatística - IBGE (2010). No total, 3,4\% da população residente no Brasil possui deficiência visual. É imprescindível que equipamentos e recursos sejam desenvolvidos e estejam disponíveis para esta parcela da população ser incluída na sociedade.

De acordo com a Fundação Dorina Nowill (2018), recursos e serviços utilizados para auxiliar pessoas com deficiência são conhecidos como Tecnologia Assistiva. Quando se trata de pessoas com deficiência visual esta inclui aplicativos para celular, hardwares, softwares, aparelhos de escuta assistida, instrumentos para escrita em Braille como reglete e máquina de escrever, entre outras tecnologias.

O Sistema Braille é importante para o aprendizado de crianças e adultos com deficiência visual, ele desperta o gosto pela leitura e elimina barreiras de comunicação, torna possível ler e escrever em diversas línguas, além de dar mais autonomia para essas pessoas. Louis Braille desenvolveu a primeira versão do Sistema Braille em torno de 1825, conforme Baptista (2000), este sistema foi adaptado ao longo do tempo e hoje inclui 63 sinais, que são representados por celas Braille, abrangendo letras, números, pontos e traços.

Comumente a cela Braille é composta por 6 pontos em alto relevo, organizados em 3 linhas e 2 colunas, que combinados formam um sinal Braille (Figura 1). Para Nicolaiewsky, Correa (2008), o conjunto de várias celas Braille forma uma linha Braille, a leitura dos sinais é realizada da esquerda para a direita, como na leitura convencional. O leitor pode utilizar uma ou duas mãos para tatear as celas, dependendo da sua agilidade.

Figura 1 - Representação da Cela Braille

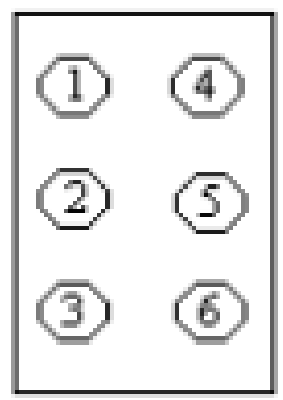

Fonte: Bezerra et al. (2003) 
No campo da Tecnologia Assistiva são encontrados equipamentos eletrônicos chamados de linha Braille ou Display Braille que, quando conectados ao computador, convertem as informações digitais em informações táteis. $\mathrm{O}$ display Braille possui uma linha de celas Braille, onde pinos são acionados para formar uma frase. (COOK; POLGAR, 2015).

Em relação ao custo, um display Braille de 16 celas custa em média $\mathrm{R} \$ 6.650,00$ no Brasil (Mundo da Lupa, 2017), sendo que no país o salário mínimo vigente em 2018 é de $\mathrm{R} \$ 954,00$ (G1, 2018). De modo que seriam necessários 6,97 salários mínimos para compra do mesmo, tornando-o inacessível para grande parte da população. Para que as pessoas com deficiência visual tenham maior acesso a este tipo de tecnologia é necessário que o custo da mesma diminua e que novas tecnologias mais acessíveis sejam desenvolvidas. A segui citar-se-ão os artigos e projetos antecedentes e relevantes para a elaboração do presente trabalho.

No artigo de Cho et al. (2006) foi projetada uma cela Braille portátil utilizando seis motores lineares piezelétricos. Os autores discutiram os detalhes da cela e realizaram testes com sete pessoas com deficiência visual para validar o projeto.

No projeto de Fukuda et al. (2011) foi fabricado um display Braille sheet-type utilizando uma tensão de $4 \mathrm{~V}$. O display é composto de transistores de película fina (TFT) orgânicos e atuadores poliméricos flexíveis.

Schmidt, Gustavo e Ramirez (2014) apresentam um conceito de um display com uma única célula Braille, onde para seu uso desenvolvem uma interface de software nos padrões de acessibilidade para deficientes visuais utilizados pela IBM e Microsoft, que se comunica com o hardware proposto. A eficiência do projeto foi apresentada por testes realizados com voluntários com deficiência visual.

Em Motto Ros et al. (2014) é desenvolvido um display tátil dinâmico baseado em tecnologia piezoelétrica buscando oferecer alta resolução. Este display permite ao usuário a escolha dos principais parâmetros da leitura Braille, onde o layout e o tempo de renderização em Braille podem ser personalizados. Os autores implementaram e testaram o display proposto e obtiveram uma boa aceitação dos oito leitores Braille que participaram do teste. 
O dispositivo prototipado por Duarte et al. (2016) tem o intuito ajudar na alfabetização de pessoas cegas ou com baixa visão. A tecnologia assistiva apresentada pelos autores utiliza de solenoides para compor uma cela Braille de seis pontos, que ativa os solenoides necessários para compor caracteres. Os autores fazem protótipos para computador e smartphone utilizando os softwares do ambiente Arduino e o MIT App Inventor, respectivamente.

Schmidt et al. (2017) apresentam um sistema de leitura Braille estático por meio de uma única cela, projetado para interações computacionais levando em conta os padrões de acessibilidade do IBM. No projeto foram integrados reconhecimento de voz, feedback auditivo e os modos de operação treinamento e leitura. O sistema, que foi testado e avaliado por três usuários cegos, visa um novo modo de aprendizado em Braille de maneira eficiente.

Este artigo tem como enfoque apesentar o projeto de uma cela de baixo custo que possa ser utilizada para a leitura em Braille, aumentando a acessibilidade a este tipo de tecnologia assistiva. Para a utilização do dispositivo o usuário deve dispor de um computador com porta USB para conectá-lo, bem como do programa realizado no software Arduíno IDE, que será mencionado posteriormente. Diferente do display Braile, neste equipamento o usuário deve manter o dedo parado sobre a cela e os pinos que a compõem serão acionados conforme a necessidade de formar cada caractere do alfabeto. A velocidade de leitura (troca dos caracteres) pode ser controlada com o uso de um botão auxiliar.

\section{MATERIAL E MÉTODO}

\subsection{Material}

Os pontos da cela em relevo podem ser lidos utilizando o tato, cada combinação representa um símbolo, letra ou número. A modo de exemplo, a (Figura 2) ilustra a representação do caractere " $r$ ".

Figura 2 - Representação de caracteres em Braille 


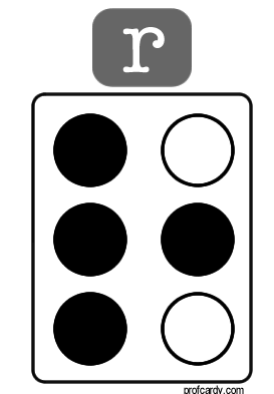

Fonte: Meier (2018)

O projeto da cela Braille foi desenvolvido para que o usuário a utilize de modo estático, ou seja, sua mão deve ficar parada sobre o dispositivo enquanto os caracteres vão mudando conforme o texto a ser lido. Para atender o critério de baixo custo foi escolhido utilizar 6 atuadores solenoides com a função de formar a cela Braille, onde cada solenoide possui um pino que compõe um dos pontos da cela.

Optou-se por fabricar a cela em uma impressora 3D utilizando o polímero ABS que, além de ser mais barato que outros polímeros que poderiam ser utilizados para esta aplicação, possui boas propriedades mecânicas, principalmente, sua alta resistência ao impacto, que se reflete na durabilidade da peça fabricada. $O$ custo por quilo do filamento ABS com 1,75mm de espessura é R \$119,90. Já outros polímeros, que também possuem boas propriedades mecânicas, como o PLA e o PETG custam, respectivamente, R\$ 129,90 e R \$149,90 o quilo. A massa da estrutura é 87 gramas, portanto o custo da mesma é de $\mathrm{R} \$ 10,43$.

Foi realizado um levantamento para selecionar o solenoide que atendesse ao máximo às necessidades do projeto e possuísse um baixo custo. Os solenoides escolhidos para o projeto são de uma empresa da China, o custo por unidade com o frete é de US\$ 1,36, totalizando $\mathrm{R} \$ 4,42$ na cotação do dia 27 de fevereiro de 2018.

Os aspectos ergonômicos foram feitos em base na NBR 13994, que normaliza as dimensões de celas Braille de elevadores em milímetros, conforme a (Figura 3).

Figura 3 - Cela Braille NBR 


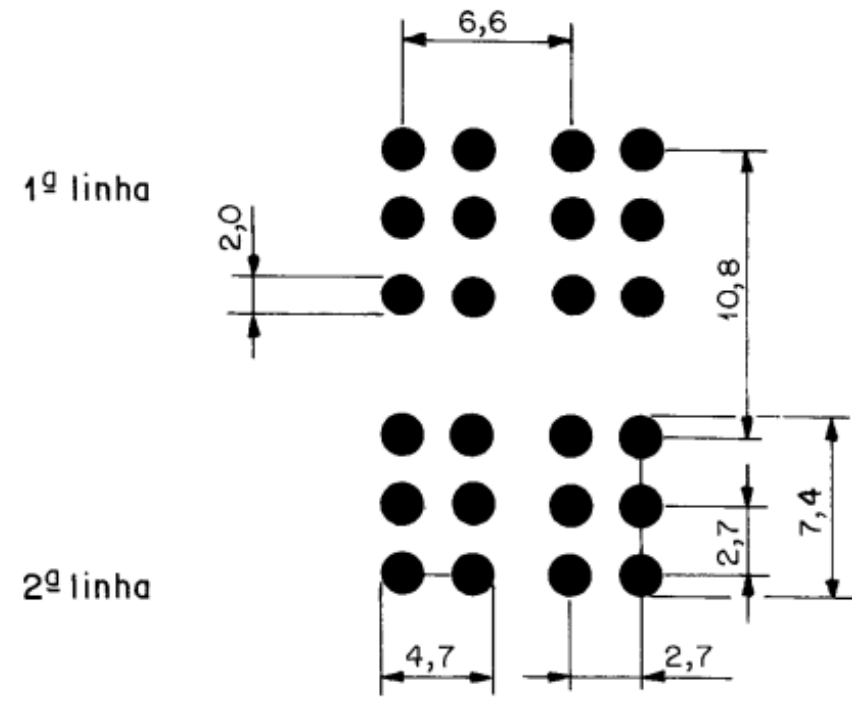

Fonte: NBR 13994 (2000)

No mercado não haviam atuadores solenoides pequenos o suficiente para respeitar as medidas exatas da NBR 13994, e visto que no trabalho de Schmidt et al., (2017) a cela Braille também era estática e foi testada e aprovada por três usuários cegos, a cela Braille foi desenvolvida utilizando medidas semelhantes às do dispositivo projetado em Schmidt et al., (2017), acrescentando apenas 1mm na distância entre os pontos verticais no atual projeto. As medidas finais em milímetros podem ser observadas na (Figura 4).

Figura 4 - Cela Braille

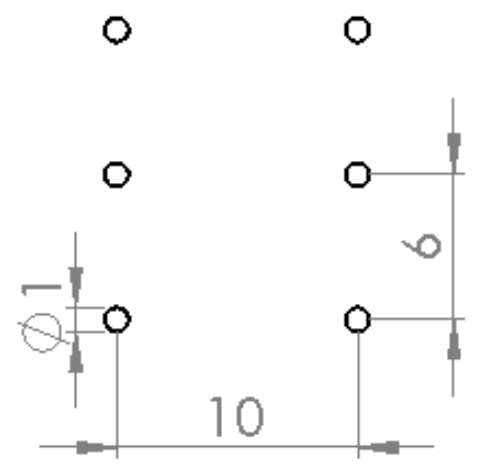

Fonte: Arquivo pessoal (2018)

O Quadro 1 apresenta os materiais que utilizados no projeto bem como a quantidade e os custos.

Quadro 1: Materiais

\begin{tabular}{|l|l|l|l|}
\hline Material & Quantidade & Custo unitário & Custo total \\
\hline Polímero ABS & 87 gramas & $\mathrm{R} \$ 119,00 / \mathrm{kg}$ & $\mathrm{R} \$ 10,43$ \\
\hline
\end{tabular}

Fonte: Arquivo pessoal (2019) 


\begin{tabular}{|l|l|l|l|}
\hline Atuador Solenoide & 6 un. & $\mathrm{R} \$ 4,42$ & $\mathrm{R} \$ 26,52$ \\
\hline Arduino Uno + cabo USB & 1 un. & $\mathrm{R} \$ 39,90$ & $\mathrm{R} \$ 39,90$ \\
\hline Diodo de proteção N 4002 & 6 un. & $\mathrm{R} \$ 0,07$ & $\mathrm{R} \$ 0,42$ \\
\hline Resistor 100 OHM & 6 un. & $\mathrm{R} \$ 4,00$ & $\mathrm{R} \$ 24,00$ \\
\hline Transistor PN3568 5V 1A & 6 un. & $\mathrm{R} \$ 4,10$ & $\mathrm{R} \$ 24,60$ \\
\hline Botão Switch H & 2 un. & $\mathrm{R} \$ 1,00$ & $\mathrm{R} \$ 2,00$ \\
\hline Mini Parafuso M1 x 4,5mm & 4 un. & $\mathrm{R} \$ 0,45$ & $\mathrm{R} \$ 1,80$ \\
\hline
\end{tabular}

\section{RESULTADOS E DISCUSSÃO}

\subsection{Programação}

O programa da Cela Braille foi adaptado de uma pesquisa anterior de Schmidt et al., (2017), onde o software utilizado foi o Arduino IDE. O programa inicialmente traduzia palavras ou textos para Braille sem diferenciar letras minúsculas e maiúsculas, e números. Este também permitia que o usuário definisse a velocidade de leitura por meio da troca de caracteres. A (Figura 5) mostra o caractere que foi acrescentado no programa, que em Braille significa que a letra a seguir é maiúscula.

Figura 5 - Letra maiúscula

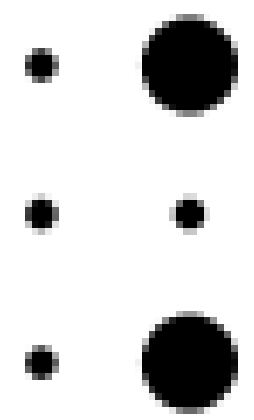

Fonte: Marcelly; Penteado (2011)

$\mathrm{Na}$ (Figura 6) pode-se observar o caractere "número", que foi acrescentado no programa para indicar os numerais. Em Braille este caractere é impresso antes de uma letra de "a" até "j" representando os números de 0 a 9. A combinação "número" mais "a" formam o número 1.

\section{Figura 6 - Número 1}




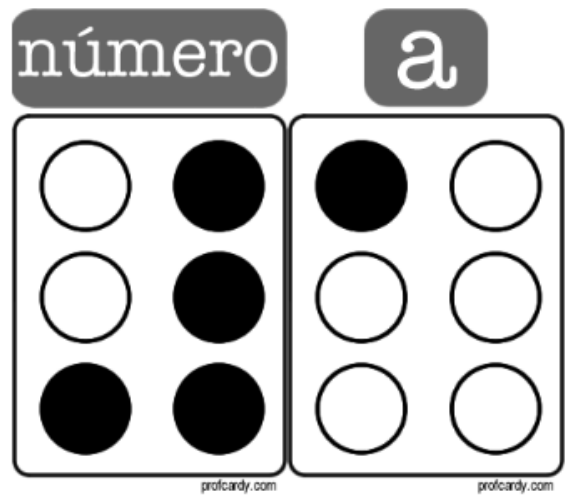

Fonte: Meier (2018)

O programa também foi alterado para adaptá-lo ao uso com atuadores solenoides, visto que anteriormente o código foi escrito para funcionar com servo-motores.

Além dos atuadores solenoides o hardware do dispositivo é composto pela placa Arduino Uno, por um cabo USB, de seis diodos de proteção e de seis transistores. A placa possui 14 entradas digitais, sendo estas suficientes para o projeto, e opera a $5 \mathrm{~V}$. Para que esta funcione é necessário um cabo USB que armazena o programa do Arduino IDE no mesmo e, quando conectado a uma fonte, o alimenta. O custo da placa com o cabo USB é de $\mathrm{R} \$ 39,90$, dos seis diodos de proteção é de $\mathrm{R} \$ 0,42$ e dos seis transdutores é de $\mathrm{R} \$$ 24,60. A visão do hardware, composta pelo Arduino UNO, resistores, transistores, diodos de proteção e solenoide pode ser observada na (Figura 7). Na figura são apresentados apenas um resistor, um transistor e um solenoide, estes no hardware real repetem-se seis vezes.

Figura 7 - Visão do Hardware

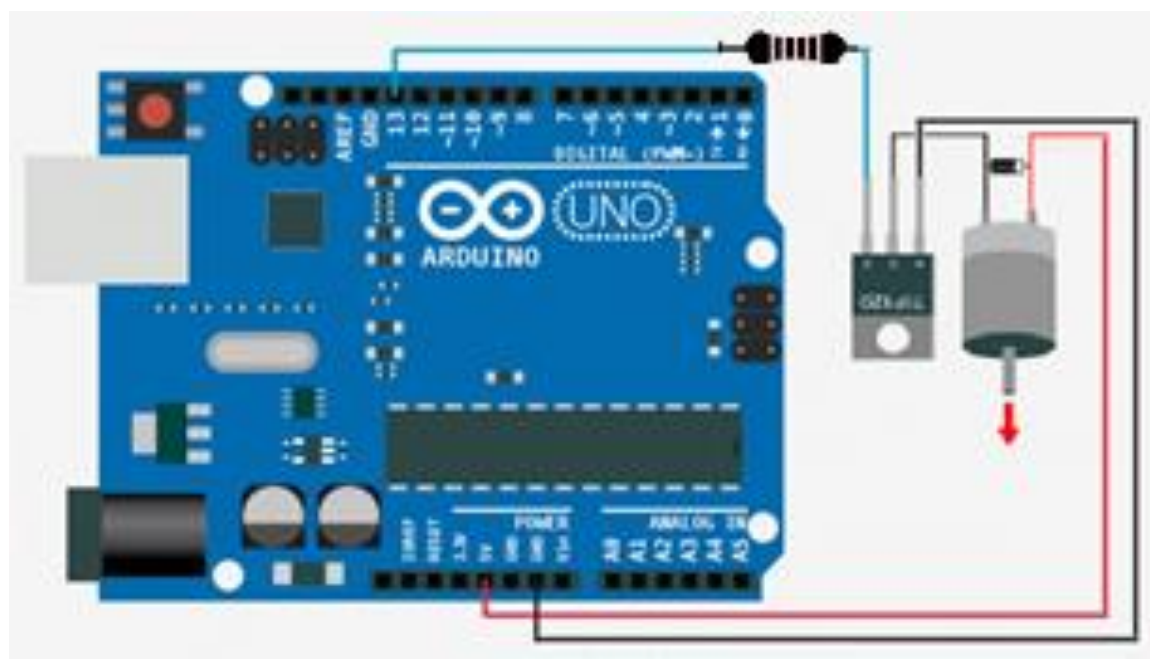

Fonte: Adaptado de Bildr, Mercado Libre e Ultra Coloring Pages (2019) 
Como os solenoides foram encomendados da China e o serviço de entrega não os entregou em tempo hábil, validou-se o programa utilizando LEDs para representar os solenoides. Os testes foram realizados com uma placa Arduino Uno, seis LEDs, uma protoboard e o programa escrito no Arduino IDE. Os LEDs acesos representavam os solenoides com pino acionado, e os LEDs apagados representavam os solenoides com pino não acionado. Os testes realizados em laboratório incluíram todo o alfabeto latino e números de 0 a 9 . Os caracteres foram testados individualmente e em pequenos textos. Caracteres maiúsculos e minúsculos foram incluídos no início, meio e fim das frases testadas, bem como os números. O programa executou os testes perfeitamente, imprimindo letras maiúsculas e minúsculas, e números com a diferenciação adequada.

\subsection{Projeto}

O dispositivo foi projetado pensando em conforto e ergonomia, é pequeno e busca atender usuários de diversas idades e tamanhos de mão diferentes. A cela fica do lado esquerdo, onde o dedo indicador deve estar posicionado, do lado direito há um botão de avançar, onde o dedo médio deve estar posicionado, e na lateral esquerda do dispositivo há um botão liga/desliga que pode ser acionado pelo polegar. Pode-se observar a estrutura do dispositivo na (Figura 8).

Figura 8 - Dispositivo

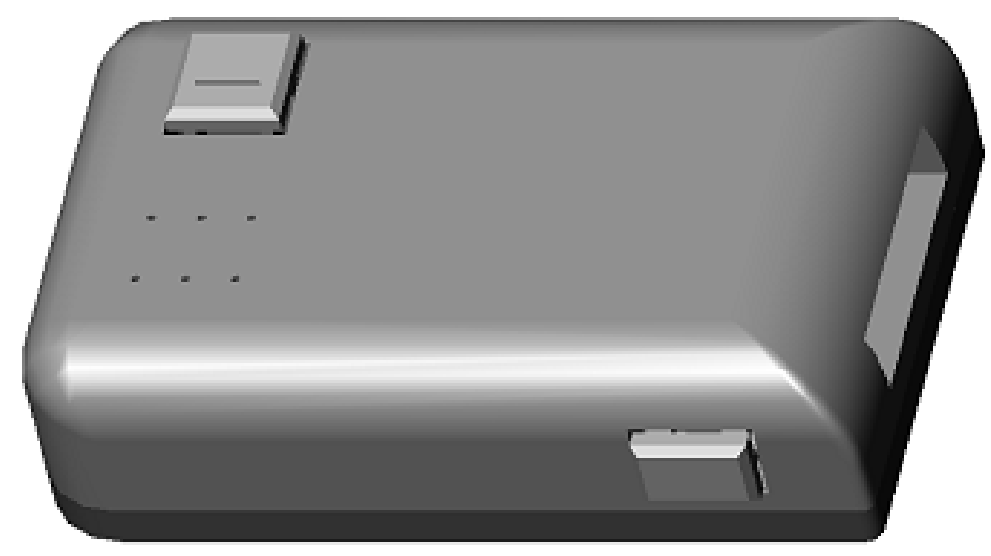

Fonte: Arquivo pessoal (2018)

Para facilitar a montagem a estrutura do dispositivo possui uma base, onde os solenoides serão encaixados, e uma parte superior, que contém os dois botões. A união 
dos componentes será realizada utilizando quatro Mini Parafuso M1 x 4,5mm com custo unitário de R\$0,45. A (Figura 9) mostra o topo do dispositivo e a base lado a lado.

Figura 9 - Topo e Base
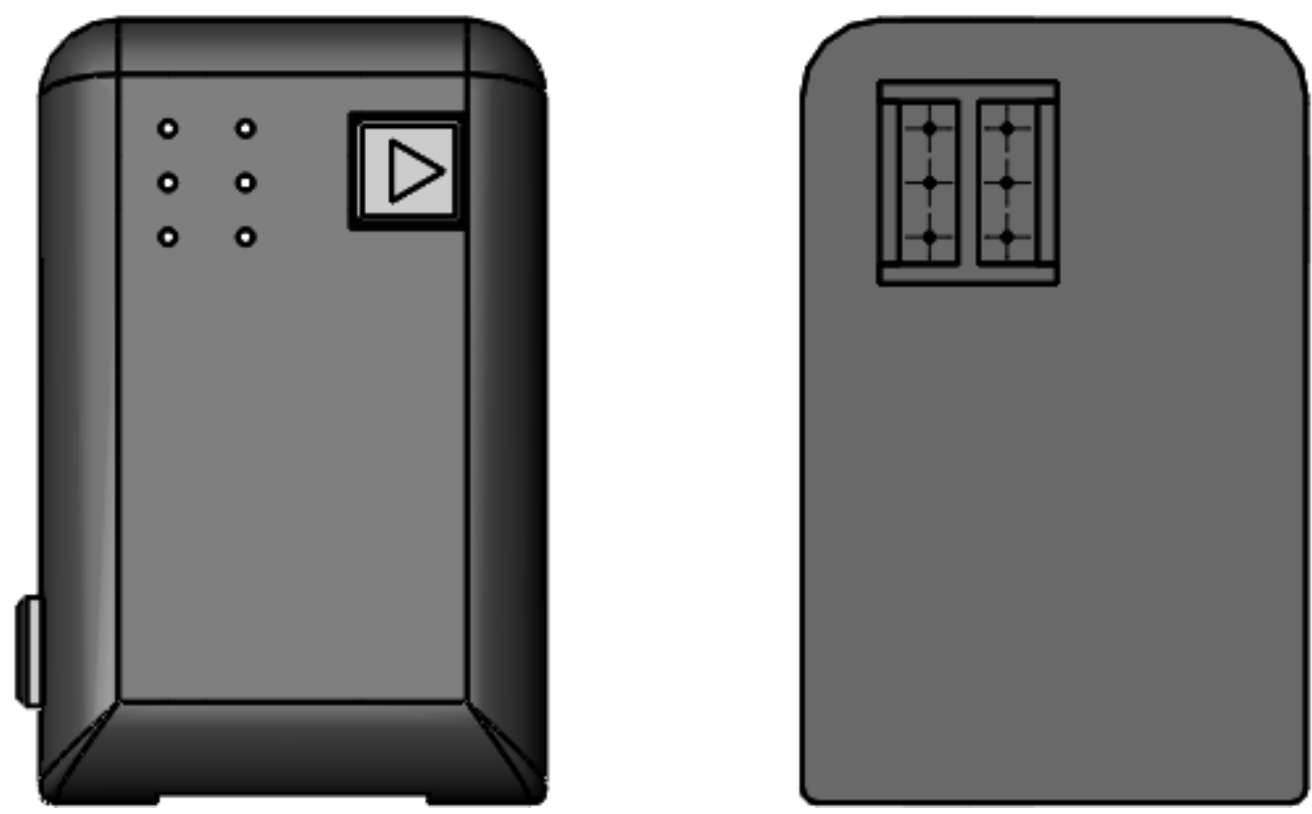

Fonte: Arquivo pessoal (2018)

Uma simulação do dispositivo com os solenoides foi realizada em um software de

CAD 3D para melhor ilustrar seu funcionamento. Pode-se observar a formação da letra “f” em Braille na (Figura 10).

Figura 10 - Simulação da Cela Braille

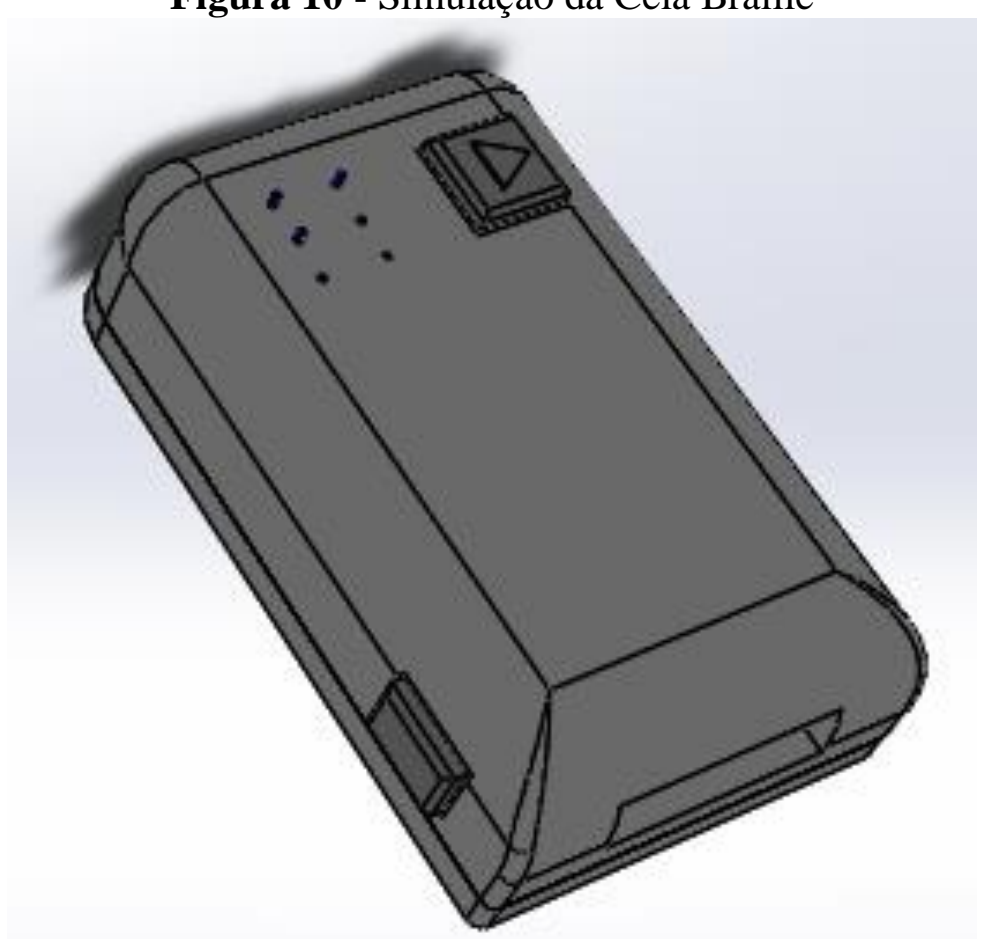

Fonte: Arquivo pessoal (2018) 
A estrutura do dispositivo foi fabricada em uma impressora 3D. Pode ser observado na (Figura 11) a peça pronta para ser montada com os solenoides.

Figura 11 - Cela Impressa

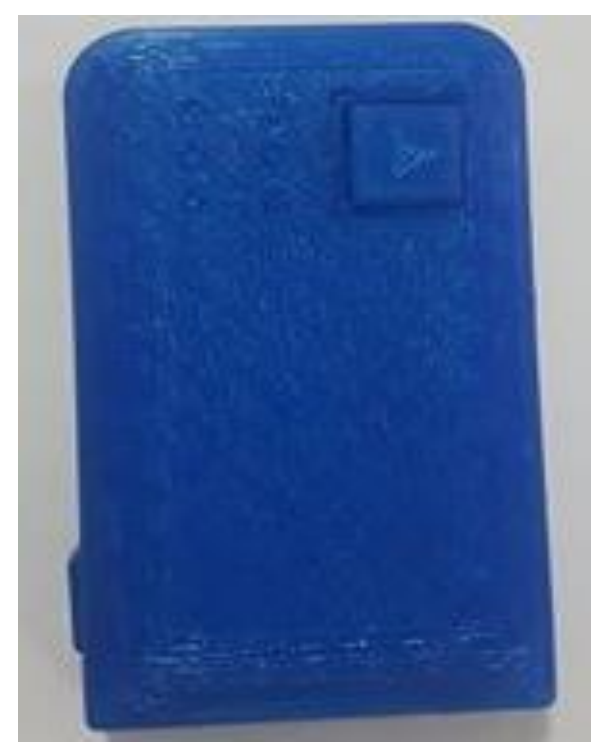

Fonte: Arquivo pessoal (2018)

Para validar o projeto realizaram-se testes de hergonomia com a avaliação do conforto do dispositivo por seis voluntáris que permaneceram com a mão direita posicionada sobre a cela por 5 minutos. A (Figura 12) mostra um comparativo dos voluntários 1 e 6 usando o dispositivo.

Figura 12 - Teste

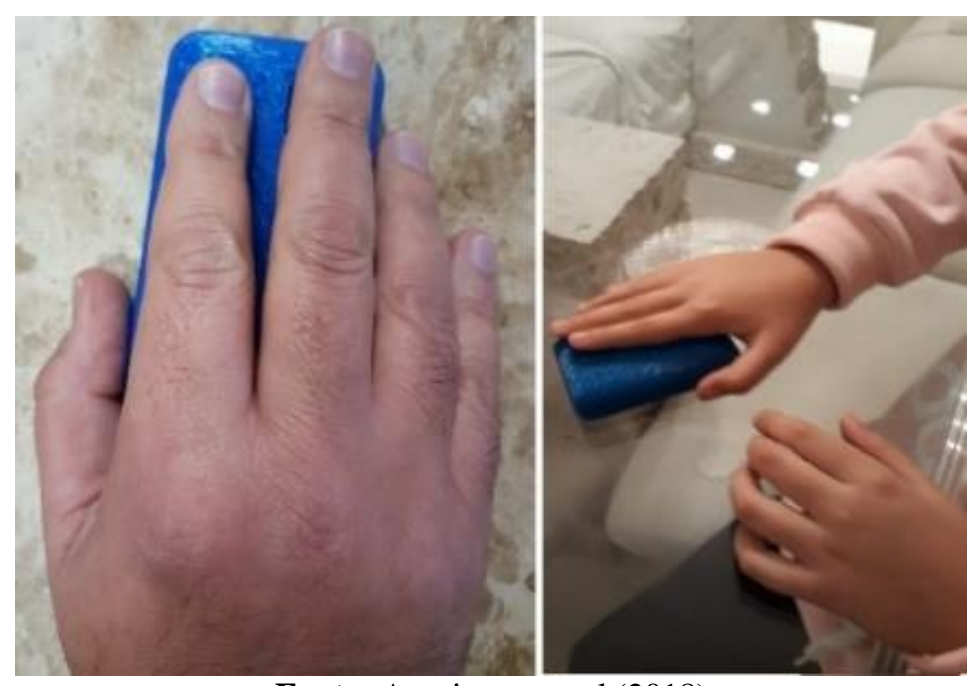

Fonte: Arquivo pessoal (2018) 
Os resultados obtitidos no teste de ergonomia estão presentes nno Quadro 2, onde pode-se observar a idade, sexo, tamanho de mão e observações sobre o conforto e o posicionamento dos botões segundo os voluntários.

\begin{tabular}{|c|c|c|c|c|}
\hline Voluntário & Idade & Sexo & $\begin{array}{l}\text { Mão } \\
(\mathrm{cm})\end{array}$ & Observações \\
\hline 1 & 55 & Masculino & 19,7 & $\begin{array}{l}\text { Não senti incomodo, consegui clicar nos botões sem } \\
\text { problemas. }\end{array}$ \\
\hline 2 & 49 & Feminino & 17,6 & $\begin{array}{l}\text { Achei confortável, consegui colocar os dedos nos } \\
\text { botões com muita facilidade. }\end{array}$ \\
\hline 3 & 23 & Maculino & 18,5 & $\begin{array}{l}\text { Parece um mouse, não senti incomodo nenhum e } \\
\text { achei confortável tanto o formato quanto a posição } \\
\text { dos botões. }\end{array}$ \\
\hline 4 & 22 & Feminino & 17,4 & A posição não é cansativa, os botões têm fácil acesso. \\
\hline 5 & 9 & Feminino & 15,2 & $\begin{array}{l}\text { É fácil e confortável, não tive dificuldade nenhuma e } \\
\text { consegui mexer nos botões. }\end{array}$ \\
\hline 6 & 7 & Feminino & 13,5 & Achei confortável e consegui apertar os botões. \\
\hline
\end{tabular}

Quadro 2: Teste de ergonomia

Fonte: Arquivo pessoal (2018)

Com os testes realizados sabe-se que o protótipo está adequado para atender mãos de $13,5 \mathrm{~cm}$ até $19,7 \mathrm{~cm}$, e como o polegar não precisa ficar posicionado no botão liga/desliga durante o uso, usuários com a mão maior ou menor do que os testados podem utilizar o dispositivo confortavelmente.

Com os testes realizados sabe-se que o protótipo está adequado para atender mãos de $13,5 \mathrm{~cm}$ até $19,7 \mathrm{~cm}$, e como o polegar não precisa ficar posicionado no botão liga/desliga durante o uso, usuários com a mão maior ou menor do que os testados podem utilizar o dispositivo confortavelmente.

\section{CONSIDERAÇÕES FINAIS}

O custo total para fabricação da Cela Braille em laboratório foi de $\mathrm{R} \$ 129,67$. Embora custos de energia elétrica, depreciação da impressora 3D, remuneração do operador de impressora 3D, remuneração do montador e impostos não tenham sido incluídos, há uma grande margem para que o dispositivo continue com um custo baixo, principalmente quando comparado com os equipamentos disponíveis no mercado para o mesmo fim. 
Neste projeto o dispositivo não foi efetivamente testado como um protótipo final, mas sabe-se que o programa escrito na plataforma Arduino IDE atende os requisitos necessários para seu funcionamento e que o dispositivo possui um tamanho adequado para que seja utilizado confortavelmente por usuários de aproximadamente 7 anos ou mais.

Para trabalhos futuros recomenda-se uma nova busca por solenoides que atendam as dimensões necessárias no mercado, ou até mesmo a fabricação dos mesmos. Testes com usuários com deficiência visual devem ser realizados, tanto com os que já leem em Braille quanto por aqueles que estão sendo alfabetizados.

\section{REFERÊNCIAS BIBLIOGRÁFICAS}

BRASIL. INSTITUTO BRASILEIRO DE GEOGRAFIA E ESTATÍSTICA. Censo: População residente por tipo de deficiência permanente, 2010. Disponível em: <https://www.ibge.gov.br/estatisticas-novoportal/sociais/populacao/9662-censodemografico-2010.html?edicao=9749\&t=destaques $>$. Acesso em: 18 fev. 2018.

BAPTISTA, J. A. L. S. A invenção do Braille e a sua Importância na Vida dos Cegos. Lisboa: Gráfica, v. 2000, n. 9, 2000.

MUNDO DA LUPA (Brasil). Linha Braille: orbit 20. 2017. Disponível em: <https://mundodalupa.com.br/produto/orbit-20/>. Acesso em: 23 fev. 2018.

G1 (Brasil). Salário mínimo em 2018: veja o valor. 2018. Disponível em: <https://g1.globo.com/economia/noticia/salario-minimo-em-2018-veja-o-valor.ghtml>. Acesso em: 17 jun. 2018.

FUNDAÇÃO DORINA NOWILL. Tecnologia assistiva. Disponível em: $<$ https://www.fundacaodorina.org.br/a-fundacao/deficiencia-visual/tecnologia-assistiva/> . Acesso em: 05 mar. 2018.

NICOLAIEWSKY, C. de A.; CORREA, Jane. Escrita ortográfica e revisão de texto em braille: Uma história de reconstrução de paradigmas sobre o aprender. Cadernos Cedes, v. 28, p. 229-244, 2008.

BEZERRA, Claudia Maria Caixeta et al. BR Braille: programa tradutor de textos Braille digitalizados para caracteres alfanumericos em portugues. 2003.

MEIER, Cardy. Braille. Disponível em: <http://www.profcardy.com/cardicas/braille/>. Acesso em: 17 jun. 2018

Educação, Psicologia e Interfaces, Volume 3, Dossiê Inclusão e Diversidade, p. 135-149, 2019 ISSN: 2594-5343. DOI: https://doi.org/10.37444/issn-2594-5343.v3i4.189 
ASSOCIAÇÃO BRASILEIRA DE NORMAS TÉCNICAS. NBR 13994: Elevadores de passageiros - Elevadores para transporte de pessoa portadora de deficiência. Rio de Janeiro, 2000. 15 p.

MARCELLY, Lessandra; PENTEADO, Miriam Godoy. A escrita matemática em braille (TA). In: XIII Conferência Interamericana de Educação Matemática. 2011.

COOK; A. M.; POLGAR. J. M. Assistive technologies: principles and practices. St. Louis: Mosby Elsevier, 2015. 472 p.

$\mathrm{CHO}$, Hyun-Cheol et al. Development of a braille display using piezoelectric linear motors. In: SICE-ICASE, 2006. International Joint Conference. IEEE, 2006. p. 19171921.

FUKUDA, Kenjiro et al. A 4 V Operation, Flexible Braille Display Using Organic Transistors, Carbon Nanotube Actuators, and Organic Static Random-Access Memory. Advanced functional materials, v. 21, n. 21, p. 4019-4027, 2011.

SCHMIDT, Marcelo Bernart; GUSTAVO, Luiz; RAMÍREZ, Alejandro R. García. Single Braille Cell. In: Biosignals and Biorobotics Conference (2014): Biosignals and Robotics for Better and Safer Living (BRC), 5th ISSNIP-IEEE. IEEE, 2014. p. 1-5.

MOTTO ROS, Paolo et al. A new dynamic tactile display for reconfigurable braille: implementation and tests. Frontiers in neuroengineering, v. 7, p. 6, 2014.

DUARTE, E. A. ; BORTOLOTI, J. A. ; MAIA, D.J. ; POMARI, T. A. P. ; CORREIA, G. F. ; SANTA, J. M. V. . Dispositivo para auxílio a alfabetização para pessoas cegas ou de baixa visão. 2016.

SCHMIDT, Marcelo Bernart; METZGER, Luiz Gustavo; MORTIMER, Robert; RAMIREZ, Alejandro Rafael Garcia. New user interface using a single Braille cell approach. Informática na Educação: teoria \& prática, [s.1.], v. 20, n. 2/, p.157-168, 8 set. 2017. Universidade Federal do Rio Grande do Sul. http://dx.doi.org/10.22456/19821654.62741 .

F3DB (Brasil). Filamento abs premium $1,75 \mathrm{~mm}$ para impressora 3d cor: branco 1kg. Disponível em: <https://www.filamentos3dbrasil.com.br/abs-premium/filamentosabs-premium-175mm1/1 kg4/filamento-abs-premium-175-mm-para-impressora-3d-corbranco-1kg/>. Acesso em: 27 fev. 2018.

F3DB (Brasil). Filamento pla premium 1,75 mm para impressora 3d cor: branco 1kg. Disponível em: < https://www.filamentos3dbrasil.com.br/pla/filamentos-pla$175 \mathrm{~mm} / 1 \mathrm{~kg} 2 /$ filamento-pla-175mm-para-impressora-3d-cor-branco$1 \mathrm{~kg} /$ ?variant=6891981>. Acesso em: $27 \mathrm{fev} .2018$.

F3DB (Brasil). Filamento petg premium 1,75 mm para impressora 3d cor: branco 1kg. Disponível em: < https://www.filamentos3dbrasil.com.br/petg/filamento-petg$175 \mathrm{~mm} / 1 \mathrm{~kg} /$ filamento-petg-175mm-para-impressora-3d-cor-branco1/>. Acesso em: 27 fev. 2018. 
UOL (Brasil). Câmbio: Dólar Comercial. Disponível em:

$<$ https://economia.uol.com.br/cotacoes/cambio/dolar-comercial-estados-unidos/>. Acesso em: 27 fev. 2018.

ARDUINO Uno Rev3 R3 Atmega328 Smd Com Cabo Usb. Disponível em: $<$ https://www.americanas.com.br/produto/18088756/arduino-uno-rev3-r3-atmega328-smdcom-cabo-usb?epar=buscape\&hl=lower\&opn=YYNKZB\&s_term=YYNKZB >. Acesso em: 04 jun. 2018.

MINI Parafuso M1 x 4,5mm Metálico - Kit com 10 unidades. Disponível em: $<$ https://www.usinainfo.com.br/parafusos-e-fixadores/mini-parafuso-m1-x-45mmmetalico-kit-com-10-unidades-3428.html?search_query=Mini+Parafuso\&results=47> . Acesso em: 04 jun. 2018.

BOTÃO Switch $\mathrm{H}=6 \times 6 \times 5 \mathrm{mBotão}$ Switch $\mathrm{H}=6 \times 6 \times 5 \mathrm{~mm}$ Para Arduinom Para Arduino. Disponível em: <https://produto.mercadolivre.com.br/MLB-742723756-boto-switch-h6x6x5>. Acesso em: 04 jun. 2018.

BILDR. High-Power Control: Arduino + TIP120 Transistor. Disponível em: <https://bildr.org/2011/03/high-power-control-with-arduino-and-tip120/>. Acesso em: 28 ago. 2019.

MERCADO LIBRE. PUENTE H Driver Motor De Tb6612fng Arduino. Disponível em: $<$ https://articulo.mercadolibre.com.co/MCO-453091177-puente-h-driver-motor-dctb6612fng-arduino-_JM?quantity=1>. Acesso em: 28 ago. 2019.

ULTRA COLORING PAGES. RESISTOR DESENHO PARA COLORIR. Disponível em: <http://www.ultracoloringpages.com/pt/p/resistor-desenho-paracolorir/811c9c7fb85d30ff68b068c59c32001f >. Acesso em: 28 ago. 2019.

\section{Credenciais do(a) autor(a)}

TORRES, Heloise Dellagnelo - Graduanda em Engenharia Mecânica na Universidade do Vale do Itajaí/Brasil. E-mail: heloisetorres@edu.univali.br

RAMIREZ, Alejandro Rafael Garcia - Mestre e Doutor em Engenharia Elétrica pela Universidade Federal de Santa Catarina. Professor nos cursos de graduação em Engenharia de Computação e Engenharia Mecânica e no curso de Mestrado em Computação Aplicada da Universidade do Vale do Itajaí/Brasil. E-mail: ramirez@univali.br

Endereço para correspondência: Heloise Dellagnelo Torres. E-mail: heloisetorres@edu.univali.br

Como citar este artigo (Formato ABNT): TORRES, Heloise Dellagnelo; RAMIREZ, Alejandro Rafael Garcia. Projeto de uma cela Braille de baixo custo. Educação, Psicologia e Interfaces, v. 3, Dossiê Inclusão e Diversidade, p. 135-149, 2019. DOI: https://doi.org/10.37444/issn-2594$\underline{5343 . v 3 i 4.189}$

Recebido: 08/10/2019.

Aceito: 20/10/2019.

Educação, Psicologia e Interfaces, Volume 3, Dossiê Inclusão e Diversidade, p. 135-149, 2019 ISSN: 2594-5343. DOI: https://doi.org/10.37444/issn-2594-5343.v3i4.189 